\title{
Cannabidiol (CBD): a strong plea for mandatory pre-marketing approval of food supplements
}

\author{
Dirk W. Lachenmeier ${ }^{1}$ (D) Stephan G. Walch ${ }^{1}$ (I)
}

Received: 1 April 2020 / Accepted: 4 April 2020 / Published online: 16 April 2020

(c) The Author(s) 2020

The case of cannabidiol (CBD) makes the deficits in the current regulatory approach for food supplements clearly evident. Therefore, we strongly urge for a paradigm shift towards pre-marketing approval. The issue of CBD products mass marketing, typically in form of so-called CBD oils (i.e., hemp extract mixed into edible oil), started in 2018. According to Google Trends (2020), the interest in CBD in Germany strongly increased during 2018 and peaked from August to November 2019 and is currently on the decline, but still on a high level ( $80 \%$ of peak interest).

The regulatory approach for CBD is specifically difficult. "Extracts and tinctures" from the hemp plant Cannabis sativa may be considered narcotic or psychotropic substances within the meaning of the United Nations Single Convention on Narcotic Drugs (1961) and could therefore be excluded from being a food or food supplement according to Regulation (EC) No 178/2002. Furthermore, CBD could be a medicinal product, and likewise be excluded from being "food". Indeed, some EU member states such as France enforce a restrictive policy and consider CBD as being a narcotic drug. Others, such as Denmark, Ireland or Germany consider CBD as food product and try to enforce the requirements of the food law. Some CBD products are currently marketed as "non-food" (e.g., CBD room scents) in a questionable manner to circumvent any narcotic, medicinal or food laws, but these products would still be covered by the food definition of Regulation (EC) No 178/2002 as these products are reasonably expected to be ingested by humans.

We believe that it would be disproportional to regulate CBD products as narcotic drug, according to the principle of "ultima ratio" in criminal law, while the pharmacological action required to regulate $\mathrm{CBD}$ as medicinal product is

Dirk W. Lachenmeier

Lachenmeier@web.de

1 Chemisches und Veterinäruntersuchungsamt (CVUA) Karlsruhe, Weissenburger Strasse 3, 76187 Karlsruhe, Germany difficult to substantiate (Lachenmeier et al. 2019). Therefore, it is reasonable to regulate CBD products as food supplements within the requirements of food law, such as Regulation (EC) No 178/2002 regarding general food safety requirement, Directive 2002/46/EC relating to food supplements, Regulation (EU) No 1169/2011 regarding food information, and Regulation (EC) No 1924/2006 on nutrition and health claims.

Food control authorities in Europe have reported various offences of food business operators selling CBD products against the European food law. More than 100 notifications regarding $\mathrm{CBD}$ as unauthorised novel food ingredient and unauthorised tetrahydrocannabinol (THC) in CBD product were shared in the Rapid Alert System for Food and Feed (RASFF). The Food Safety Authority of Ireland (FSAI) reported that from 38 tested CBD products, $37 \%$ exceeded the safe limit of THC dosage set by EFSA $(1 \mu \mathrm{g} / \mathrm{kg}$ body weight/day), 34\% were classified as novel food lacking approval, 36\% were food supplements lacking the necessary notification of the competent authority, $92 \%$ were tested to contain differences between analytical and declared CBD content of more than $10 \%$, and finally $50 \%$ contained misleading claims such as unauthorised health claims or medicinal claims (FSAI 2020). Very similar results were published from our own institute. Within the category of cannabidiol products, the quota of offences was $100 \%$, meaning that every single sample showed some violation, starting with lack of novel food approval, deficits in mandatory labelling requirements, or the use of non-approved health claims, or prohibited disease-related claims, but most critically, 46 out of 67 samples (69\%) showed THC dosages above the EFSA limit (Lachenmeier et al. 2020).

However, extreme quotas of offences against food law are not restricted to CBD supplements. Actually, in official food control practice, the category of foods for particular nutritional uses has the highest rate of complaints among all food categories, e.g., $23.1 \%$ of all official samples evaluated in this category in Germany in 2018 showed violations against 
the food law (BVL 2019). If we look at the sub-category of food supplements, this quota is even higher. For example, in the German Federal State of Baden-Württemberg, 77\% of all evaluated samples of food supplements had violations (own data for 2019).

In the EU, the food business operator has the primary responsibility to ensure the requirements of food law. Obviously, some food business operators, and specifically those selling CBD, do not have any intention to do so. Actually for $\mathrm{CBD}$, this would mean to end the current activity and waiting for the novel food approval of the compound. In the context of other food supplements, it would mean to stop marketing products with unapproved or overstated health claims, disease-related claims or other misleading claims, which typically is the basis for a consumer wanting to buy such a supplement. Hence, we constantly see supplement products beyond legality, which are still placed on the market with the knowledge that enforcement of food control including the typical judicial proceedings has such a long lag-time that the product is sold out before ultimately forbidden, and the cat-and-mouse game can start with slightly modified products from the beginning. Normally, the consumer is only economically disadvantaged by misleading supplements, but sometimes, as in the case of $\mathrm{CBD}$, the consumer health might be at risk, when the undeclared presence of THC can pose a risk for children, drivers, as well as athletes who may be buying and consuming these products without knowing they contain a psychotropic substance (FSAI 2020).

We believe that the current legal system for food supplements as specified in Directive 2002/46/EC on the approximation of the laws for the Member States relating to food supplements has proven to be completely inefficient and ineffective. Recital \#4 of the directive states: "In order to ensure a high level of protection for consumers and facilitate their choice, the products that will be put on to the market must be safe and bear adequate and appropriate labelling". This goal has clearly not been reached in almost 20 years of application of the directive. Therefore, we suggest a paradigm shift towards pre-marketing approval. The current notification procedure should be amended by mandatory pre-market verification of composition as well as labelling.
Specific rules should be made for nutrients and other substances besides vitamins and minerals, most preferably by positive lists with minimum/maximum approved amounts; i.e., everything is forbidden, if not specifically allowed.

Acknowledgements Open Access funding provided by Projekt DEAL.

Open Access This article is licensed under a Creative Commons Attribution 4.0 International License, which permits use, sharing, adaptation, distribution and reproduction in any medium or format, as long as you give appropriate credit to the original author(s) and the source, provide a link to the Creative Commons licence, and indicate if changes were made. The images or other third party material in this article are included in the article's Creative Commons licence, unless indicated otherwise in a credit line to the material. If material is not included in the article's Creative Commons licence and your intended use is not permitted by statutory regulation or exceeds the permitted use, you will need to obtain permission directly from the copyright holder. To view a copy of this licence, visit http://creativecommons.org/licenses/by/4.0/.

\section{References}

BVL (2019) Jahresbericht 2018 der Bundesrepublik Deutschland zum mehrjährigen nationalen Kontrollplan nach VO (EG) $\mathrm{Nr}$. $882 / 2004$. Bundesamt für Verbraucherschutz und Lebensmittelsicherheit, Berlin

FSAI (2020) Consumers being put at risk and misled with some CBD food supplements, Food Safety Authority of Ireland, https://www. fsai.ie/news_centre/press_releases/cbd_food_supplement_surve y_130220.html. Accessed 18 Mar 2020

Google Trends (2020) Suchbegriff: CBD, Google. https://trends.googl e.de/trends/explore?q=CBD\&geo $=$ DE $\&$ date $=2013-01-01 \% 20$ 2020-03-11\#TIMESERIES. Accessed 13 Mar 2020

Lachenmeier DW, Bock V, Deych A, Sproll C, Rajcic de Rezende T, Walch SG (2019) Hemp food products—an update. Deut Lebensm Rundsch 115(8):351-372

Lachenmeier DW, Habel S, Fischer B, Herbi F, Zerbe Y, Bock V, Rajcic de Rezende T, Walch SG, Sproll C (2020) Are side effects of cannabidiol (CBD) products caused by tetrahydrocannabinol (THC) contamination? F1000Res 8:1394

Publisher's Note Springer Nature remains neutral with regard to jurisdictional claims in published maps and institutional affiliations. 